\title{
Multiple pterygium syndrome: evolution of the phenotype
}

\author{
E M THOMPSON*, D DONNAI†, M BARAITSER*, C M HALL*, \\ M E PEMBREY $\ddagger$, AND J FIXSEN* \\ From *The Hospital for Sick Children, Great Ormond Street, London WC1N 3JH; the Department of \\ Medical Genetics, St Mary’s Hospital, Whitworth Park, Manchester M13 OJH; and ¥Mothercare Unit of \\ Paediatric Genetics, Institute of Child Health, 30 Guilford Street, London WC1N 1EH.
}

SUMMARY The clinical features of the multiple pterygium syndrome are multiple congenital joint contractures, multiple skin webs, camptodactyly, vertebral anomalies, short stature, ptosis, and antimongoloid eye slant. We present 11 new cases to show the evolution of the full phenotype from birth and to confirm autosomal recessive inheritance. We emphasise morbidity secondary to respiratory impairment and that conductive deafness may be part of the syndrome.

The designation multiple pterygium syndrome was used by Gorlin et al in 1976 to describe an autosomal recessive disorder characterised by congenital arthrogryposis, skin webs (pterygia) across joints, and an unusual facies. A review by Escobar $e t$ $a l^{2}$ led to the alternative name Escobar syndrome, quoted by Smith. ${ }^{3}$ Hall et $a l^{4}$ summarised findings in 42 reported cases adding seven new patients. Differentiation from other causes of congenital arthrogryposis may be difficult at birth since the typical facial appearance, pattern of finger contractures, and obvious webs usually develop over the first few years of life.

We report 11 new cases of the syndrome to confirm the recessive mode of inheritance, to improve the diagnostic criteria, and to emphasise the uncertain prognosis. We suggest that conductive deafness may be part of the syndrome.

\section{Cases}

Case histories are presented in the following section. The clinical features are summarised in table 1 and the radiological abnormalities are presented in table 2 and the appendix. Selected radiographs are shown in fig 1 .

\section{Case reports}

PATIENT 1 (MALE, III.8, FIG 2)

Patient 1 was born at term by normal delivery to a 38

Received for publication 24 August 1986.

Revised version accepted for publication 15 October 1986 year old mother and 51 year old father who are first cousin Pakistanis. Three older sibs are well. At birth he weighed $2.83 \mathrm{~kg}$ and had multiple joint contractures (fig $3 \mathrm{a}$ ) including fixed hyperextension of the knees, flexion deformity of the hips, valgus deformity of the feet, bilateral elbow flexion, and adduction of the thumbs. There was a left inguinal hernia, a cleft of the posterior palate, and the neck was short with no webbing. Lymphocyte chromosome analysis was normal $(46, X Y)$. At two years two months, during hospital admission for investigation of recurrent chest infections and failure to thrive (weight only $6.8 \mathrm{~kg}$, OFC $47 \mathrm{~cm}$ ), the joint abnormalities were still present and associated with limitation of movement. The chest was small and there was a mild scoliosis. Diagnoses considered then included pseudotrisomy 18, trisomy 8 mosaicism, and Freeman-Sheldon syndrome. The joint contractures were treated surgically; postoperatively the knees and hips could be fully extended and flexed.

When patient 1 was six years old, one of us (MB) saw a cousin (patient 2), then two months old. The similarity of their joint abnormalities prompted a review of an earlier photograph of patient 1 which showed axillary webbing (fig $3 b$ ). A diagnosis of multiple pterygium syndrome was made in the two cousins. Patient 1 was re-evaluated at the age of seven years ten months when he weighed $10.9 \mathrm{~kg}$ and was $96 \mathrm{~cm}$ tall (below the 3rd centile). The characteristic facial appearance had developed, with ptosis, antimongoloid palpebral fissures, low set ears, and micrognathia (fig 3c). Severe kyphoscoliosis was present and multiple webs had developed in the axillary, elbow, and intercrural regions. Neck 
webbing was marked laterally and in the posterior nuchal region (fig 3d). He had flexion deformities at the proximal interphalangeal joints and adducted thumbs. There was limitation of movement at the knees and at the hips there was $30^{\circ}$ of fixed flexion. Intellectual development appeared normal. He suffered recurrent chest infections.

Patient 2 (Male, IV.4, fig 2)

Patient 2 is the fourth child of first cousin Pakistani parents and related to patient 1 (see fig 2). He weighed $3.12 \mathrm{~kg}$ at term after a normal pregnancy

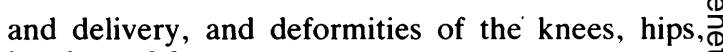
hands, and feet were apparent.

At two months, his chin was small, the ears were $\overrightarrow{\bar{F}}$ posteriorly rotated, and there were severe deform $-\overrightarrow{0}$ ities of his feet, with a rockerbottom appearance and $\frac{\mathrm{C}}{\sigma}$ vertical tali (fig 4a). Both hips were dislocated and $\bar{c}$. the knees and hips were held in flexion. The spine $\widehat{\nabla}$ was straight clinically and radiologically. The palate was intact but highly arched and there was camp-c todactyly of the fingers and adducted thumbs (fig $\vec{O}$ 4b). At eight months he began to sit and at $15-\overrightarrow{-}$ months he could stand, cruise holding on, and $\bar{\omega}$

TABLE 1 Clinical features in 11 patients with multiple pterygium syndrome.

\begin{tabular}{|c|c|c|c|c|c|c|c|c|c|c|c|c|c|}
\hline \multicolumn{6}{|l|}{ Familial cases } & \multicolumn{8}{|c|}{ Sporadic cases } \\
\hline Patient & 1 & 2 & 3 & 4 & 5 & 6 & 7 & 8 & 9 & 10 & 11 & Total & \\
\hline Age (y) & $710 / 12$ & $23 / 12$ & $\begin{array}{c}\text { Died at } \\
6 \mathrm{wk}\end{array}$ & 30 & $\begin{array}{l}\text { Died at } \\
8\end{array}$ & $1211 / 12$ & $410 / 12$ & $\begin{array}{l}\text { Died at } \\
119 / 12\end{array}$ & $2^{1 / 2}$ & $10^{1 / 2}$ & $8^{1 / 2}$ & & $\underset{\mathbb{D}}{\square}$ \\
\hline \multicolumn{14}{|l|}{ Pterygia } \\
\hline Neck & $\stackrel{+}{\text { (lat }+ \text { post })}$ & - & - & $+(\mathrm{C})$ & $+(\mathrm{C})$ & $+(\mathrm{C})$ & + & - & + & + & - & 7 & $\frac{3}{8}$ \\
\hline $\begin{array}{l}\text { Fingers } \\
\text { (syndactyly) }\end{array}$ & - & - & - & $+(\mathrm{C})$ & $+(\mathrm{C})$ & + & + & - & - & + & + & 6 & $\overrightarrow{10}$ \\
\hline Popliteal & - & + & - & $+(C)$ & $+(C)$ & + & - & - & + & + & - & 6 & ○ొ \\
\hline Axillary & + & - & - & - & - & + & - & + & + & - & - & 4 & 0. \\
\hline Antecubital & + & - & - & - & - & + & - & + & - & - & - & 3 & 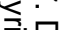 \\
\hline Intercrural & + & + & - & - & - & - & - & - & - & - & - & 2 & 흥 \\
\hline \multicolumn{13}{|l|}{$\begin{array}{l}\text { Joints } \\
\text { Multiple flexion }\end{array}$} & \\
\hline contractures & + & + & + & + & + & + & + & + & + & + & + & 11 & $\overline{\mathrm{O}}$ \\
\hline Camptodactyly & + & + & + & + & + & + & + & + & + & + & + & 11 & 응 \\
\hline Scoliosis \pm kyphosis & + & + & - & - & $+(\mathrm{C})$ & + & $+(\mathrm{C})$ & $+(\mathrm{C})$ & + & + & + & 9 & $\bar{D}$ \\
\hline Talipes (L/R) & $+1+$ & $+1+$ & $+1+$ & $+1+$ & $+1+$ & $+1+$ & $+1+$ & $-1-$ & $-1-$ & $-1-$ & $+1+$ & 8 & \\
\hline \multicolumn{13}{|l|}{ Face } & \\
\hline Micrognathia & + & + & + & + & + & + & + & + & + & + & + & 11 & 3 \\
\hline Low set ears & + & + & - & + & + & + & + & + & + & + & + & 10 & $\bar{T}$ \\
\hline Ptosis & + & - & - & + & + & + & $+(\mathrm{C})$ & + & + & + & + & 9 & $\Rightarrow$ \\
\hline Antimongoloid slant & + & + & - & + & + & + & + & + & + & - & + & 9 & ర్ \\
\hline \multirow{2}{*}{$\begin{array}{l}\text { Down turned mouth } \\
\text { Difficulty opening } \\
\text { mouth widely }\end{array}$} & - & - & - & + & + & + & + & + & + & + & + & 8 & $\widehat{3}$ \\
\hline & - & + & _ & - & + & + & + & + & + & + & + & 8 & อై \\
\hline Epicanthus & - & - & - & + & + & + & + & - & + & - & + & 6 & $\dot{\sigma}$ \\
\hline Long philtrum & - & - & - & & + & + & + & - & + & - & + & 5 & 3 \\
\hline Cleft palate & + & $\begin{array}{l}\text { High } \\
\text { arch }\end{array}$ & - & $\begin{array}{l}\text { High } \\
\text { arch }\end{array}$ & - & + & - & - & $\begin{array}{l}\text { High } \\
\text { arch }\end{array}$ & $\begin{array}{l}\text { High } \\
\text { arch }\end{array}$ & - & 2 & غุ'. \\
\hline Short stature & + & + & $?$ & + & + & + & + & + & + & + & + & 10 & 3 \\
\hline \multirow{3}{*}{$\begin{array}{l}\text { Genitalia } \\
\text { Cryptorchidism } \\
\text { Hypoplastic labia } \\
\text { majora }\end{array}$} & & & & & & & & & & & & & $\subseteq$ \\
\hline & - & + & + & & & & & & & - & - & 2 & 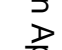 \\
\hline & & & & $?$ & + & + & + & + & - & & & 4 & 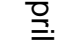 \\
\hline $\begin{array}{l}\text { Conductive hearing } \\
\text { loss }\end{array}$ & - & - & $?$ & + & + & + & - & - & $?$ & - & $(+)^{*}$ & 3 & న్ర \\
\hline Respiratory disorder & + & - & - & - & + & + & + & + & + & + & + & 8 & N \\
\hline Died & - & - & + & - & + & - & - & + & - & - & - & 3 & N \\
\hline Other & & & $\begin{array}{l}\text { CHD. } \\
\text { hypo- } \\
\text { spadias }\end{array}$ & & $\begin{array}{l}\text { Diaph- } \\
\text { ragmatic } \\
\text { hernia, } \\
\text { abnormal } \\
\text { ossicles }\end{array}$ & $\begin{array}{c}\text { Abnormal } \\
\text { ossicles }\end{array}$ & & & & & & & 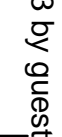 \\
\hline $\begin{array}{l}+=\text { present, }-=\text { absent, } \\
\text { (C) }=\text { congenital. CHD } \\
\text { "Mild unilateral hearing }\end{array}$ & $\begin{array}{l}?=\text { unknow } \\
=\text { congenital } \\
\text { ig loss. }\end{array}$ & wn. & & & & & & & & & & & 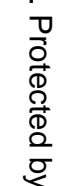 \\
\hline
\end{tabular}


'bottom shuffle'. At two years the feet still had a rockerbottom appearance and the typical facial appearance was beginning to develop (fig 4c). Additional features included inability to open the mouth widely and a relatively large head (OFC 48.5 $\mathrm{cm}, 50$ th centile; height and weight $77.9 \mathrm{~cm}$ and 8.35 $\mathrm{kg}$, respectively, both below the 3 rd centile). Webbing at the knees and in the intercrural area had developed. At 27 months a mid-thoracic scoliosis and left undescended testis were detected. Mental development was normal as were chromosomes $(46, X Y)$.

PATIENT 3 (MALE, IV.7, Fig 2)

Patient 3, born to first cousin parents, is related to patients 1 and 2 (see fig 2). At 35 weeks' gestation, the mother noticed absent fetal movements. Spontaneous vaginal breech delivery followed induction of labour at 39 weeks. Abnormalities noted at birth included marked bilateral talipes equinovarus, knees held in $70^{\circ}$ of fixed flexion, abnormal chest shape, flexion deformities of the fingers with adducted thumbs, stiff elbows, glandular hypospadias, and an undescended right testis. The ears were soft and the palate was intact. At five days, a systolic cardiac murmur was heard and by day 14 he was cyanosed and tachypnoeic and was transferred to this hospital (fig 5). His weight was then $1940 \mathrm{~g}$. Cross sectional echocardiography and cardiac catheterisation showed situs solitus with atrioven-

TABLE 2 Radiological abnormalities.

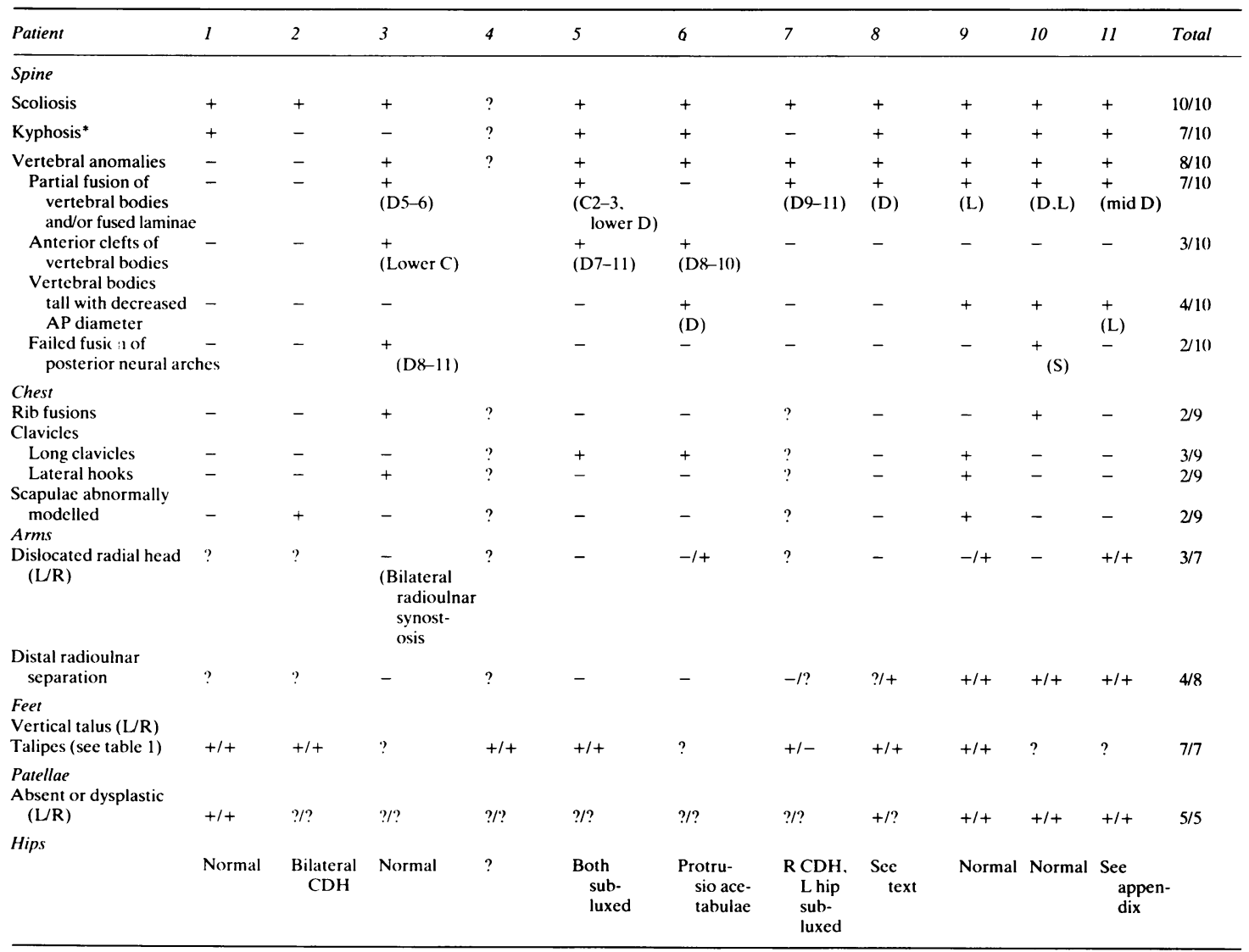

$+=$ present,$-=$ absent,$?=$ films not available.

$\mathrm{C}=$ cervical, $\mathrm{D}=$ dorsal. $\mathrm{L}=$ lumbar.

$\mathrm{L} / \mathrm{R}$ indicates left/right.

$\mathrm{CDH}=$ congenital dislocated hip.

${ }^{*}$ Note all kyphoscolioses dorsal; extended to lumbar spine in patient 9. 
E M Thompson, D Donnai, M Baraitser, CM Hall, M E Pembrey, and J Fixsen $\stackrel{\frac{1}{2}}{\stackrel{2}{2}}$
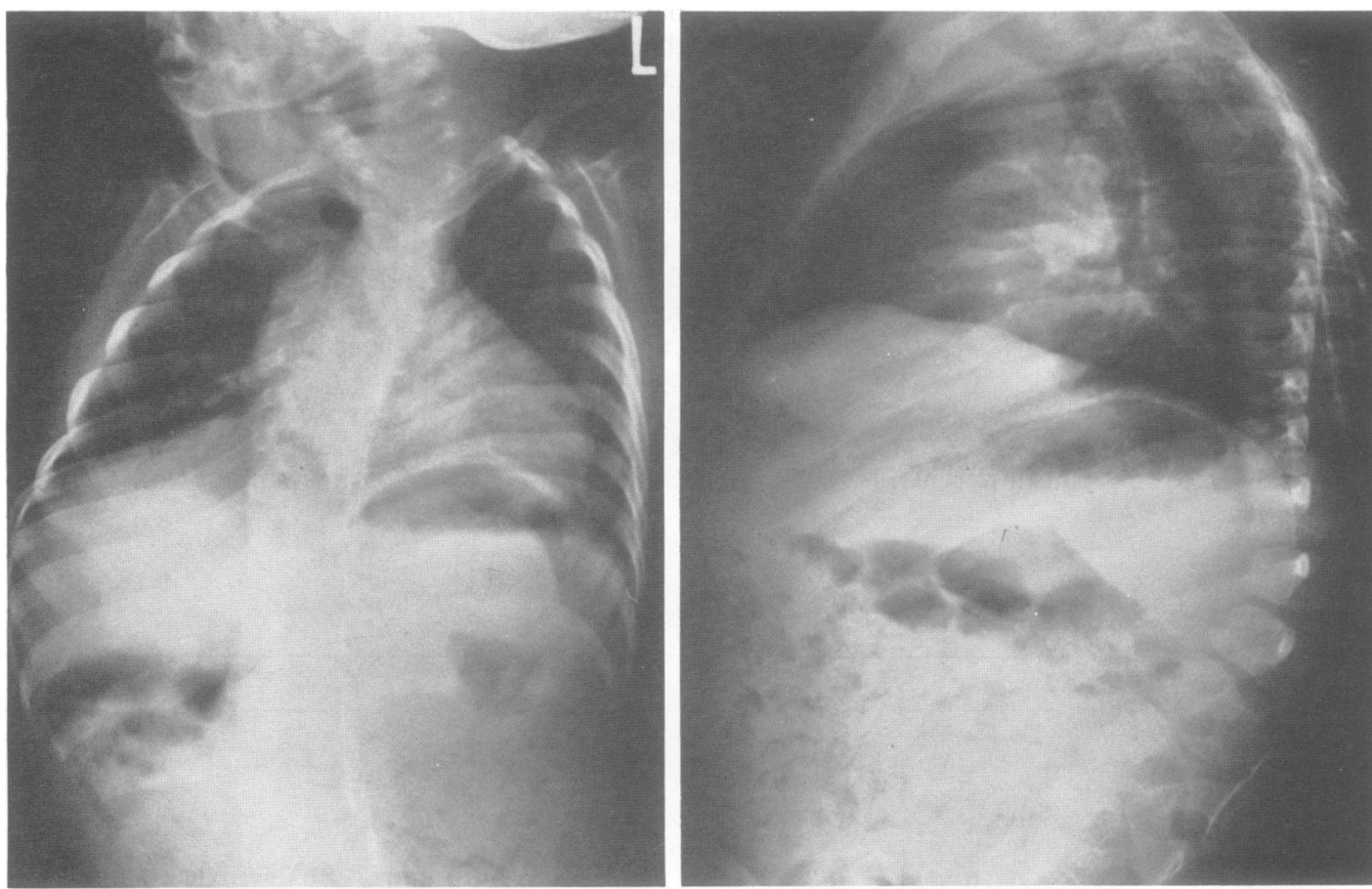

(a)

FIG 1a Spine of patient 9 at two and a half years to show dorsal kyphoscoliosis, tall and narrow vertebral bodies, and fusion of upper lumbar laminae posteriorly.

FIG $1 \mathrm{~b}$ Chest of patient 3 at two weeks to show fusion of some ribs posteriorly and partial fusion of vertebral bodies at D5-6 and anterior clefts of body of D2. 


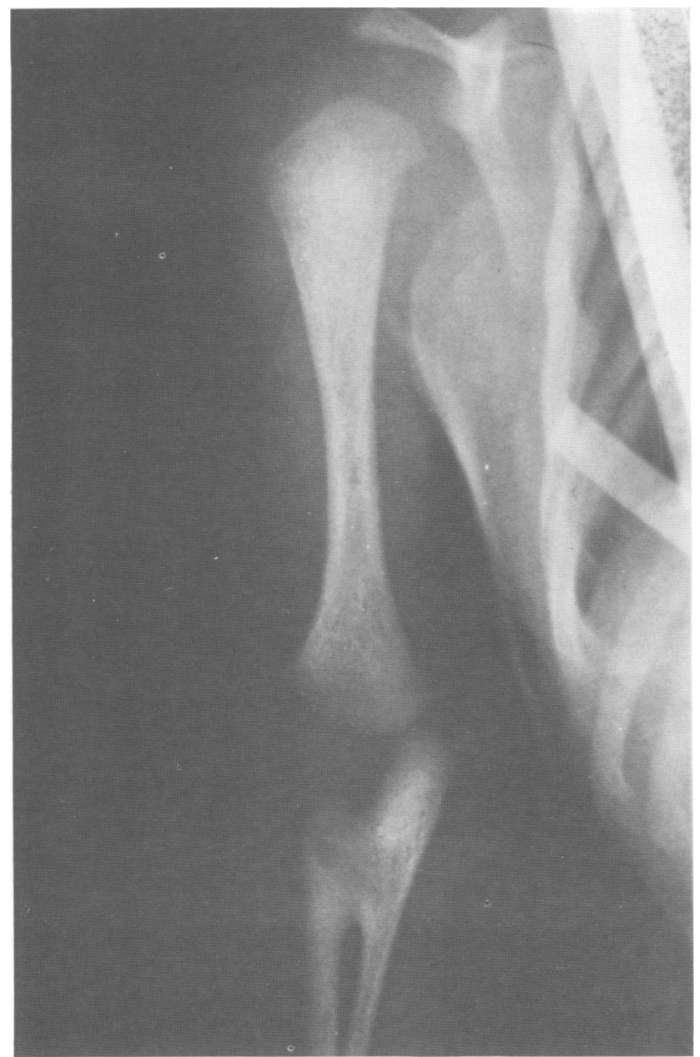

(c)

FIG 1c Right arm of patient 3 at two weeks to show radioulnar synostosis.

tricular concordance, double outlet right ventricle with an anterior large aorta, posterior confluent pulmonary arteries with a subpulmonary VSD, and subpulmonary and pulmonary stenosis. No ductus arteriosus was seen. The right ventricle was very big while the left ventricle and mitral valve were very small. The foramen ovale was patent. Balloon atrial septostomy was done with a view to a shunt procedure in future.

Although pterygia were absent, the similarity of the abnormality of the joints to those of his cousins (patients 1 and 2) led to the diagnosis of the multiple pterygium syndrome, with a complex cyanotic congenital heart disease.

The child subsequently fed well and gained weight, but he then became increasingly breathless and was readmitted to hospital, where he suddenly deteriorated and died at the age of five weeks.

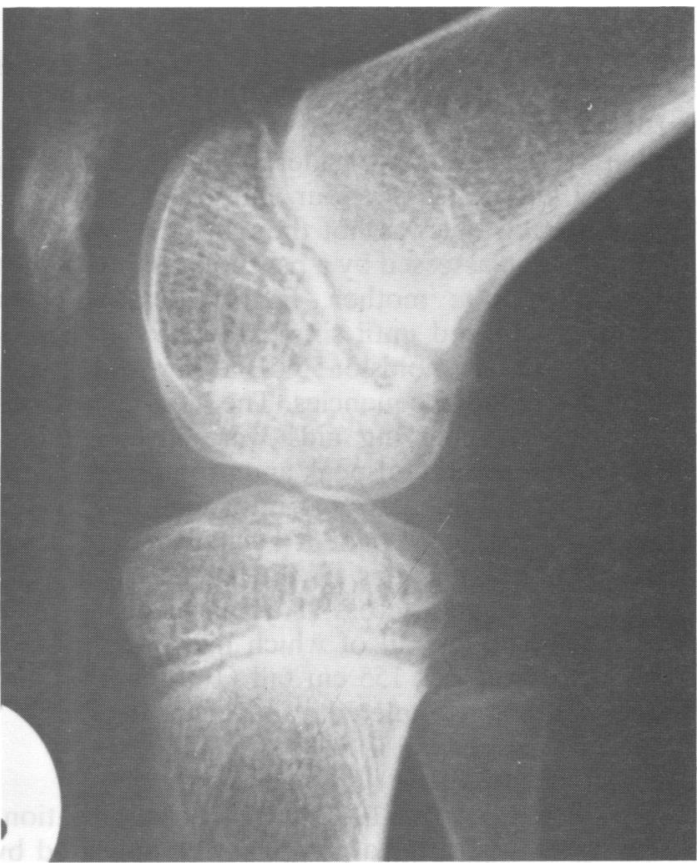

(d)

FIG 1d Knee of patient 10 at 10 years to show small, irregular, and fragmented patella.

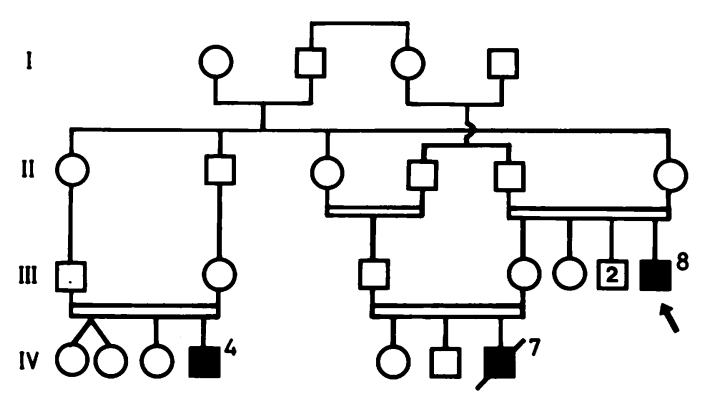

Patient 1-III.8, Patient 2-IV.4, Patient 3-IV.7

FIG 2 Pedigree for patients 1,2 , and 3.

PATIENT 4 (FEMALE)

Patient 4 (fig 6) is the first child of a healthy, unrelated, Caucasian 30 year old mother and 32 year old father. One sister is healthy but the other had the multiple pterygium syndrome (patient 5). At birth at term patient 4 weighed $3.18 \mathrm{~kg}$ and had a short neck, short legs, stiff flexed knees and hips, marked calcaneovalgus of the feet, and marked flexion at all interphalangeal (IP) joints, producing 
'clenched fists'. At 22 months she began to walk. At two and a half years, she was noted to have webbing of the neck and marked epicanthus, and bilateral vertical talus was seen on $x$ ray. The diagnosis of Turner syndrome was considered, but disproven by a normal karyotype. By four and a half years, she had no speech but was not thought to be mentally retarded when assessed by a psychologist. Although suspected by the mother, hearing loss was not formally confirmed until six years when an audiogram showed thresholds of $55 \mathrm{~dB}$ at low frequencies and $30 \mathrm{~dB}$ at high frequencies. The hearing loss was conductive and hearing aids were given. Subsequently, she learned to speak and progressed well in a normal school. Additional information obtained from the mother when patient 4 was 26 years old was that she had skin webs at the knees, neck, and between digits and across IP joints, causing fixed flexion deformities, all of which had been present since birth. She was $155 \mathrm{~cm}$ tall (10th centile) and had successfully completed a university degree.

PATIENT 5 (FEMALE)

Patient 5 was born in 1961 at 37 weeks' gestation, weighing $2720 \mathrm{~g}$, after a pregnancy complicated by

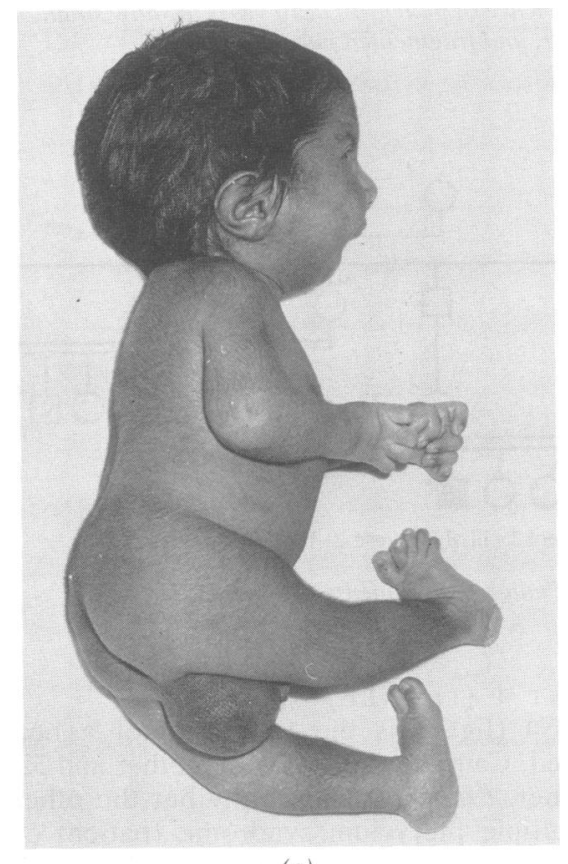

(a)

FIG 3a Patient 1 as a neonate. Note clenched fingers and rockerboitom feet, fixed flexion at hips, and fixed hyperextension at knees.

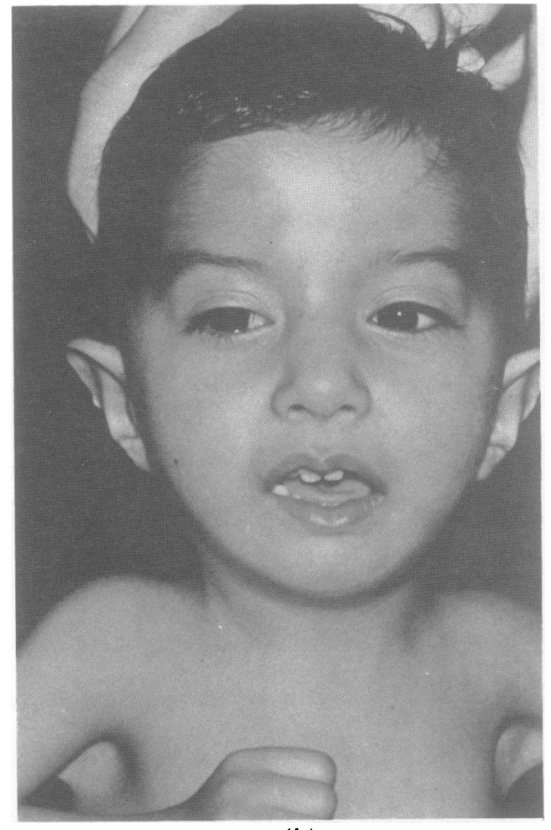

(b)

FIG 3b Patient 1 at two years. Note axillary skin webs.

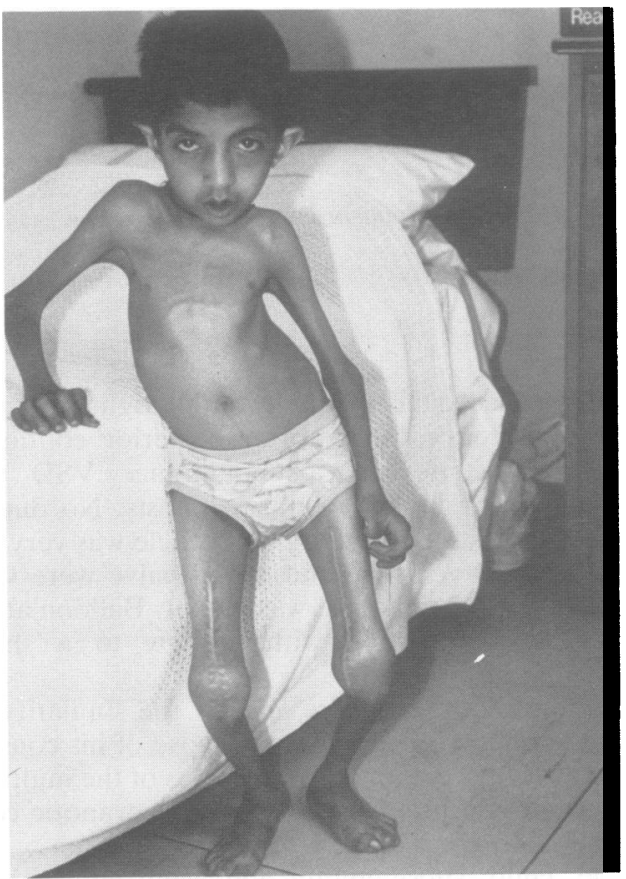

(c)

FIG 3c Patient 1 at seven years 10 months. Note ptosis, antimongoloid eye slant, axillary and right elbow webs, and hand deformities. 


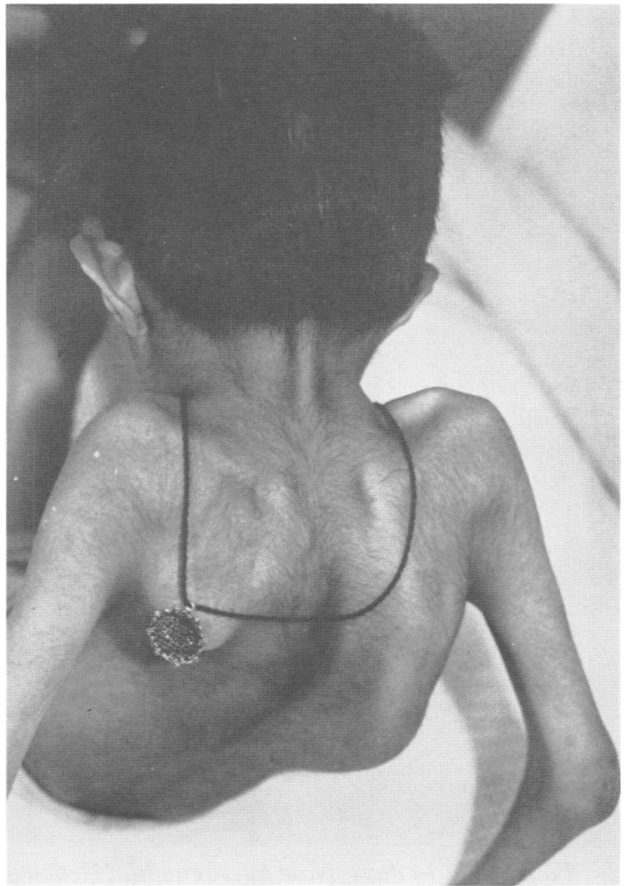

(d)

FIG 3d Patient 1 at seven years 10 months. Note posterior neck web.

hydramnios. She was the youngest sister of patient 4. At birth she had a small mouth and mandible, a very short neck with skin webbing, and a capillary haemangioma over the brow, nose, and upper lip. All large joints were stiff with flexion at the elbows, wrists, knees, and hips. The fingers were flexed so that the hands' appeared 'fisted' and the feet were in a valgus position with bilateral vertical talus (fig 7a). Popliteal skin webs and skin syndactyly were present at birth. There was a congenital thoracic scoliosis. The labia majora were noted to be hypoplastic. A right diaphragmatic hernia was repaired surgically on day 11 and recovery was uneventful. She began to sit and 'bottom shuffle' at 11 months, but did not walk alone until about three years. Intellectual and speech development were normal. A moderate low tone conductive hearing loss similar to her sister's was detected at four years. She could never open her mouth widely. Karyotype was normal $(46, X X)$. Fig 7 (b, c, d) shows her appearance at six years. She suffered from frequent chest infections and at eight years died from bronchopneumonia complicated by congestive cardiac failure and respiratory failure.

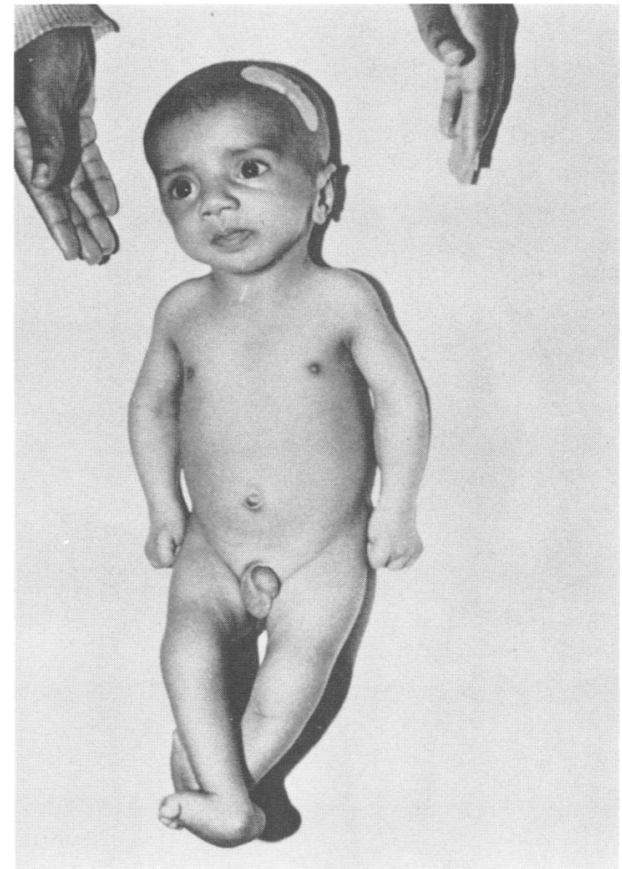

(a)

FIG 4a Patient 2 at two months. Note hand and foot deformities.

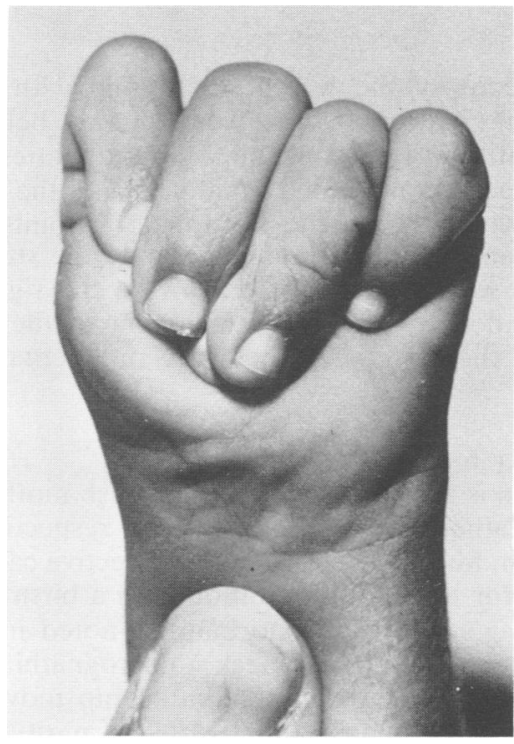

(b)

FIG 4b Patient 2. Hand at two months. Fingers are clenched with thumb held across palm. 


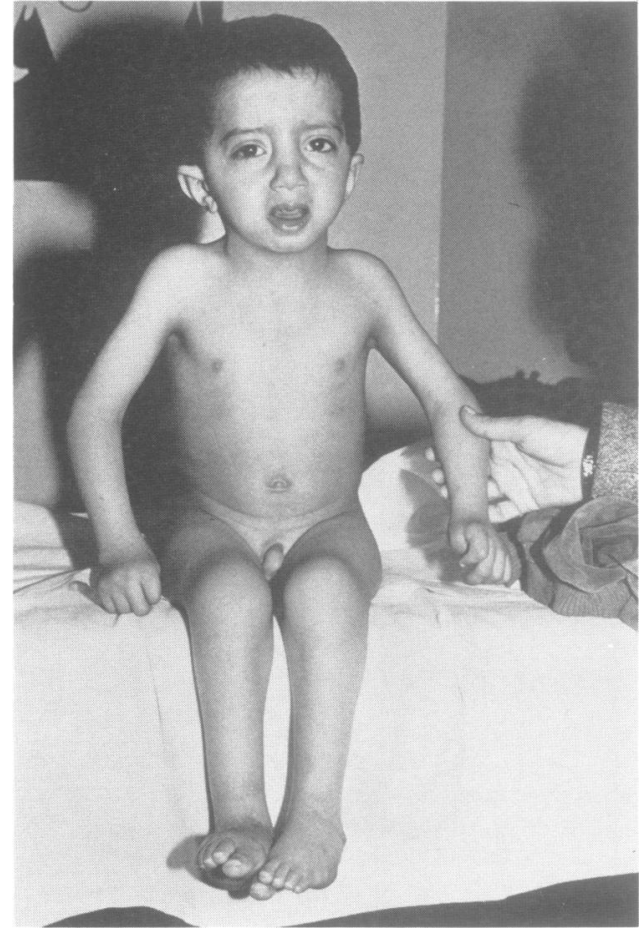

(c)

FIG 4c Patient 2 at two years. Mild antimongoloid eye slant now evident.

At necropsy she was a small child with height $116.8 \mathrm{~cm}$ (3rd centile) and weight $16 \mathrm{~kg}$ (below the 3rd centile). The congenital abnormalities were confirmed and a detailed examination of the middle ears revealed that the incus-stapes joints were fibrous and therefore ineffective, and the stapedius tendons were absent bilaterally. On the right, the incus had only a fibrous attachment to the stapes and on the left the stapes was rudimentary and fixed.

PATIENT 6 (FEMALE)

Patient 6 is the only child of an English mother and Indian father, aged 33 and 43 years respectively at her birth. She was born at term by elective caesarian section for breech presentation with a birth weight of $2555 \mathrm{~g}$. At birth, abnormalities noted included cleft palate, webbed neck, micrognathia, stiff fingers, stiff flexed knees, limited hip movement, and bilateral talipes equinovarus. Karyotype was normal $(46, X X)$. Tendon lengthening surgery was done at two and a half years. She began to walk at four years.

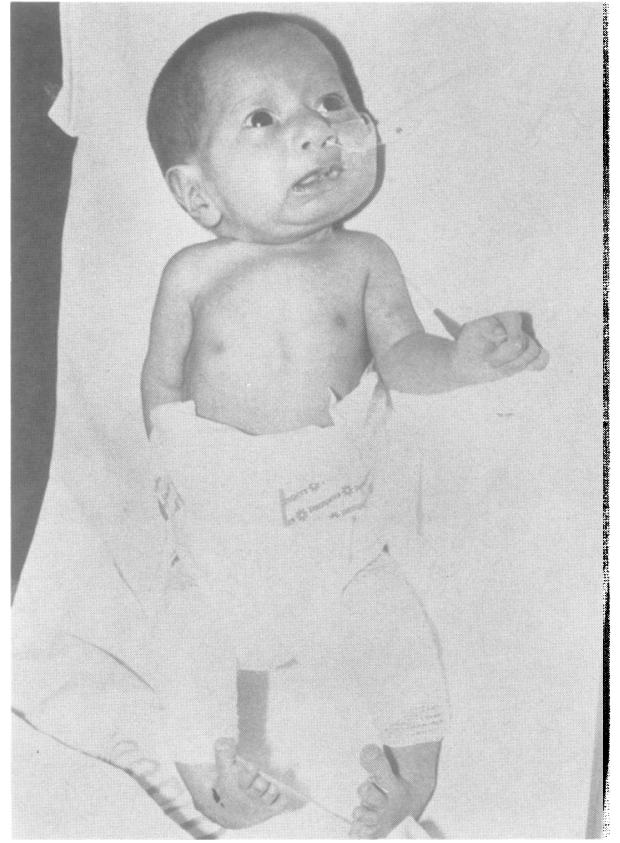

FIG 5 Patient 3 at 14 days. Note micrognathia, clenched hands, and talipes. The severe knee deformities were treate with splints.

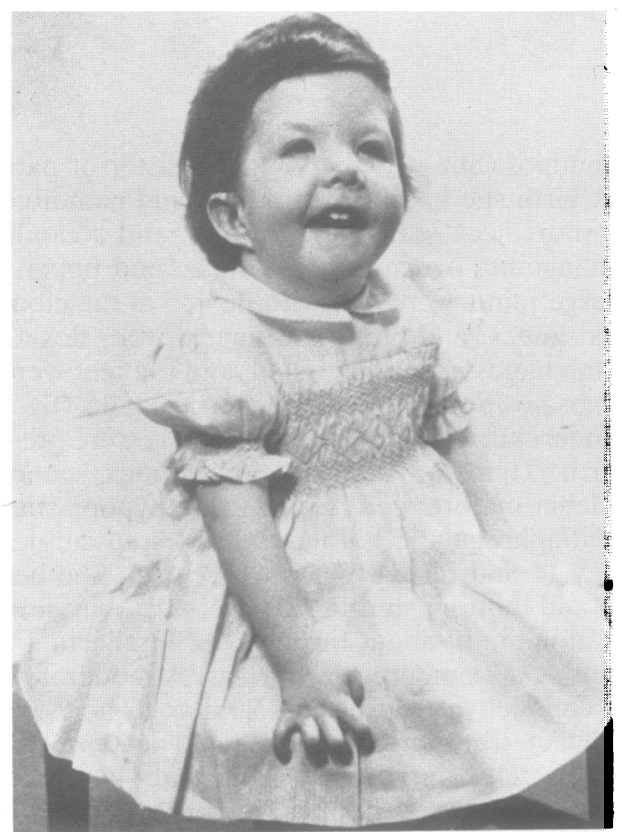

FIG 6 Patient 4 at 18 months. Note downward slanting palpebral fissures, medial epicanthus, low set ears, micrognathia, and camptodactyly. 


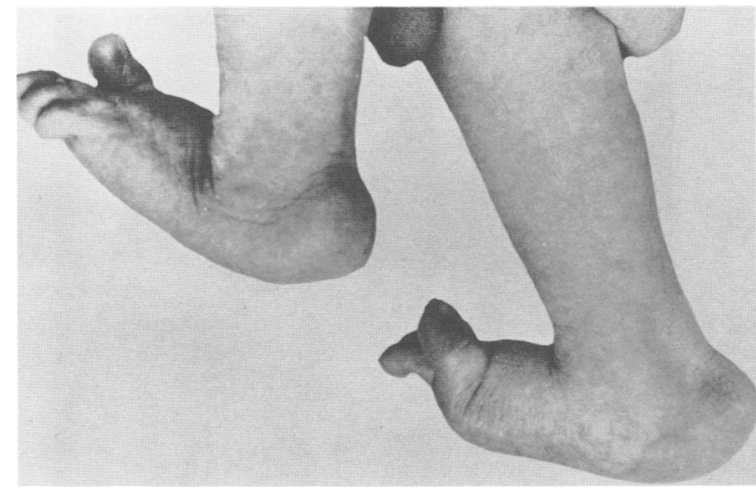

(a)

FIG 7a Feet of patient 5 at one month. Note valgus position and rockerbottom appearance.

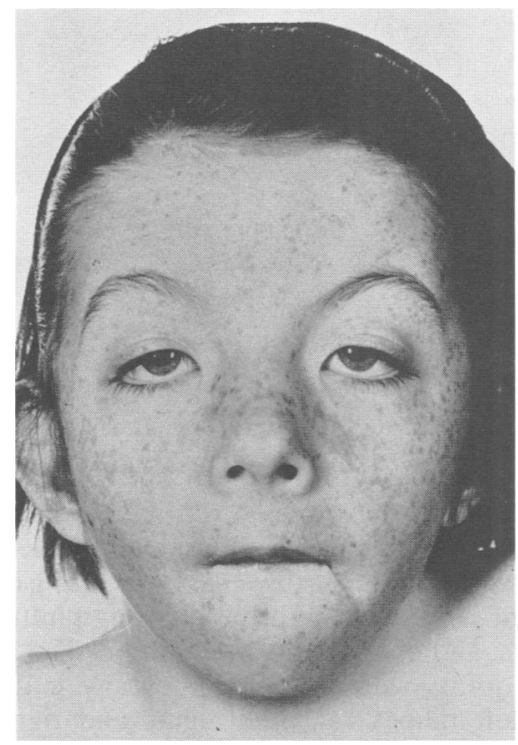

(b)

FIG 7b Patient 5 at six years. Note downward slanting palpebral fissures, ptosis, long philtrum, and small mouth.

When evaluated at six years, she had a small chin, bilateral ptosis, downward slanting palpebral fissures, epicanthic folds, down turned corners of the mouth, some indrawing of the lips, a long philtrum, and low set ears (fig $8 \mathrm{a}, \mathrm{b}$ ). She could not open her mouth widely. There was generalised weakness of the arms and legs. The knees, ankles, shoulders, elbows, and fingers were stiff with skin webbing at these joints and in the neck and intercrural region.

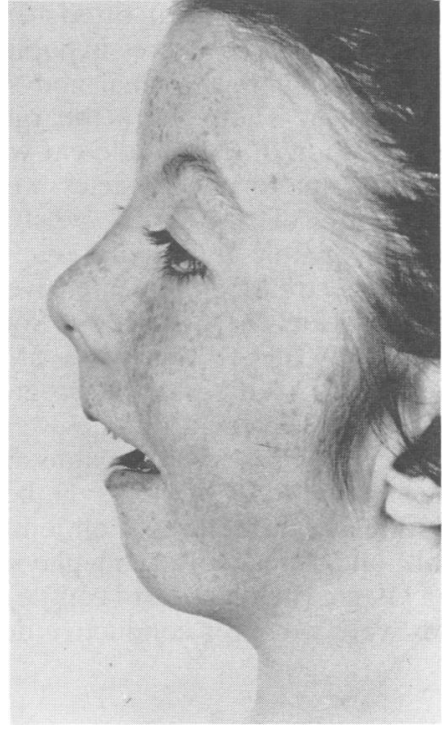

(c)

FIG 7c Patient 5 at six years. Note micrognathia and low set ears.

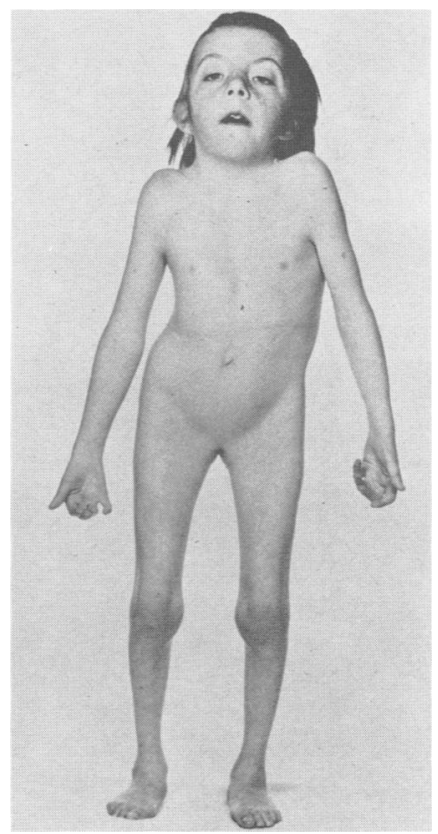

(d)

FIG 7d Patient 5 at six years. Note down turned corners of the mouth, webs at the neck and intercrural area, scoliosis, and camptodactyly. 
A Milwaukee brace had been fitted to treat scoliosis. The labia majora were hypoplastic. The cardiovascular system was normal and she was of normal intelligence. There was a hearing loss for which an exploration of the middle ear was done at five years when malformed ossicles were found. Electromyography of the right wrist extensors showed mild myopathic abnormalities.

At eight years, treatment in intensive care was required for a severe chest infection. Spinal fusion for severe kyphoscoliosis was done at 11 years. When reviewed at 13 years, she was progressing well at normal school. The hand muscles were wasted, with absent flexion creases of the palms and fingers. There was bilateral skin syndactyly between all fingers. In spite of contractures at all joints, she was able to walk and could write and play the piano. Height was $119 \mathrm{~cm}$ (below the 3 rd centile). Bilateral hearing aids were worn for conductive deafness.

PATIENT 7 (FEMALE)

Patient 7 is the fifth child of first cousin Pakistani

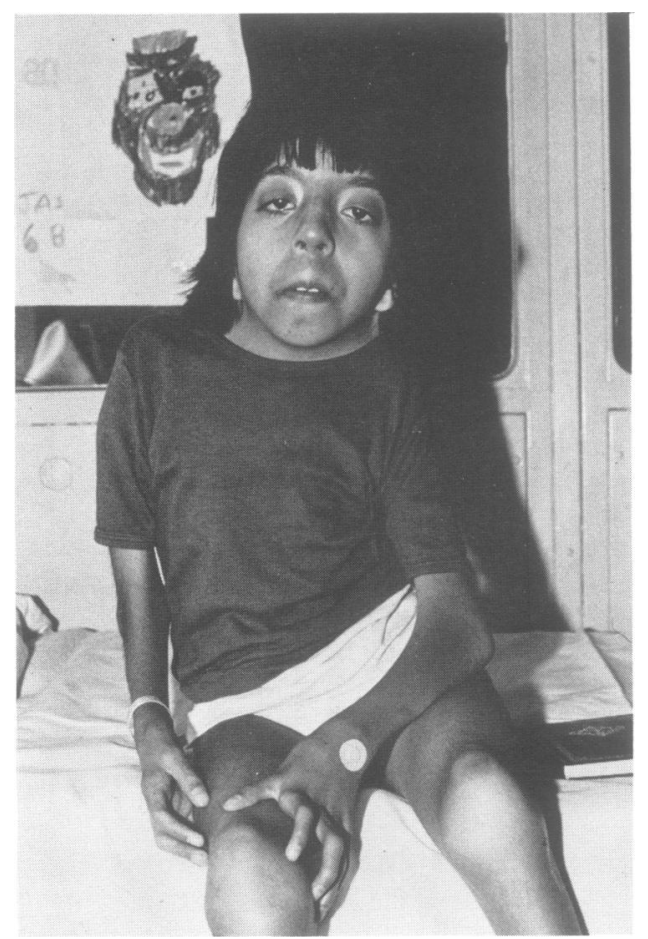

(a)

FIG 8a Patient 6 at 11 years. Note ptosis, epicanthus, downward slanting palpebral fissures and corners of mouth, long philtrum, neck webbing, scoliosis, and camptodactyly.

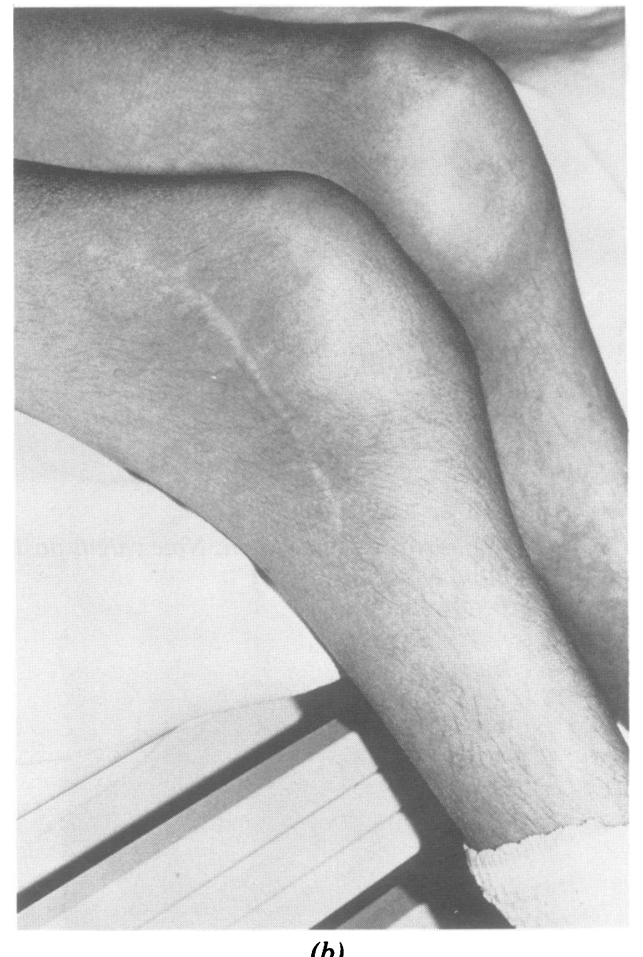

(b)

FIG $8 \mathrm{~b}$ Knees of patient 6 at 11 years showing popliteal pterygium.

parents. Her three brothers and one sister are $\overrightarrow{\overrightarrow{0}}$ healthy. Fetal movements during pregnancy were 3 reduced and there was hydramnios. The delivery, at term, was normal. Birth weight was $3325 \mathrm{~g}$ and OFC $36.5 \mathrm{~cm}$. At birth a right ptosis, long philtrum, low set ears, and hoarse voice were noted. The knee and elbow joints were stiff and there were dislocated hips, left talipes calcaneovalgus, and right talipes equinovarus. Congenital scoliosis of the dorsolumbar spine was confirmed radiologically. The hands were 'clenched' and there was hypoplasia of the $\frac{}{5}$ labia majora. At four months the child was alert and $D$ socially responsive, the neck was short, and the joints were stiff with camptodactyly of the fingers $N$ with adducted thumbs. The muscle bulk of the legs was reduced distally but power and deep tendon reflexes were normal. Creatine kinase was $82 \mathrm{U} / \mathrm{l} \omega$ (NR 10 to 145) and EMG showed no definite abnormality in the deltoid or tibialis anteriore muscles. Surgical treatment included tendon release $\mathbb{\Phi}$ at the right ankle at five months and open reduction $\stackrel{?}{+}$ of the dislocated hips at 15 and 17 months. T Subsequently, recurrence of the right hip dislocation $\frac{\vec{D}}{\mathrm{D}}$ 
occurred. She began to walk at 31 months and was admitted at four years two months for surgical correction of the left vertical talus. The only webs were at the neck and fingers (fig 9a). The latter

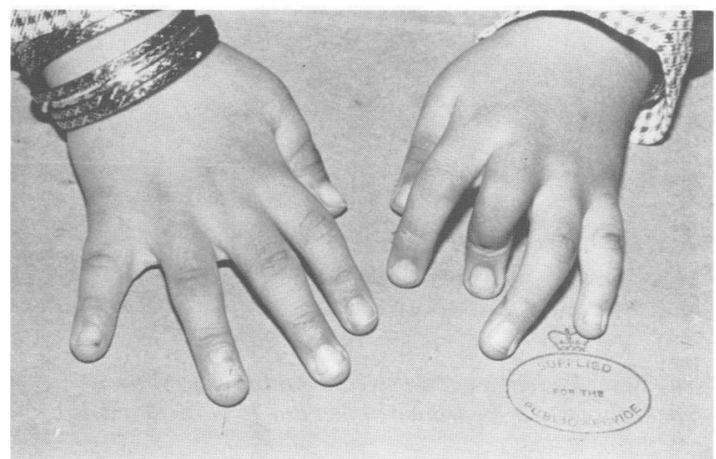

(a)

FIG 9a Patient 7 to show hands at four years. Note syndactyly on right hand. There were webs crossing IP joints on fingers 2 to 4 of left hand.

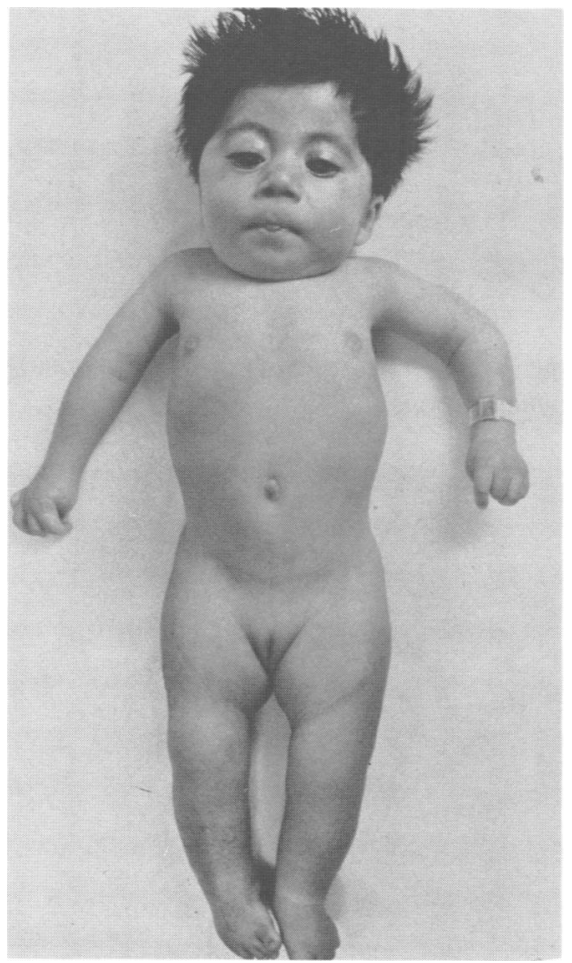

(b)

FIG 9b Patient 7 in infancy. Note ptosis and deformities of hands and feet.

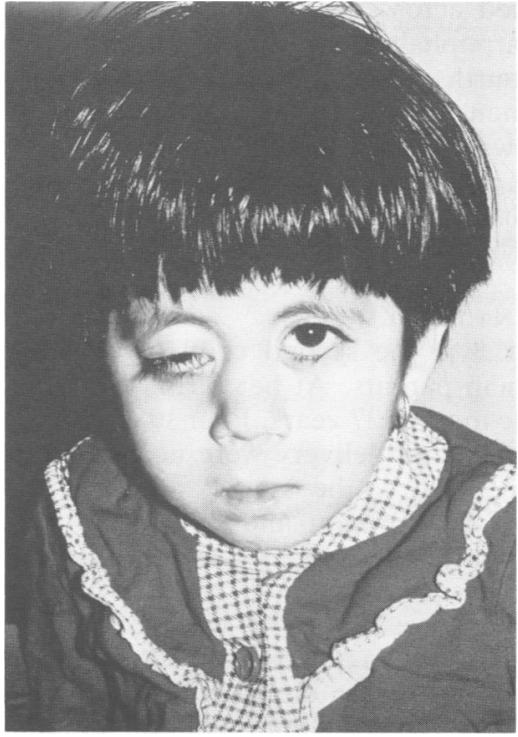

(c)

FIG 9c Patient 7 at three and a half years. Ptosis more marked on right. The sad, expressionless facial appearance is typical of the syndrome.

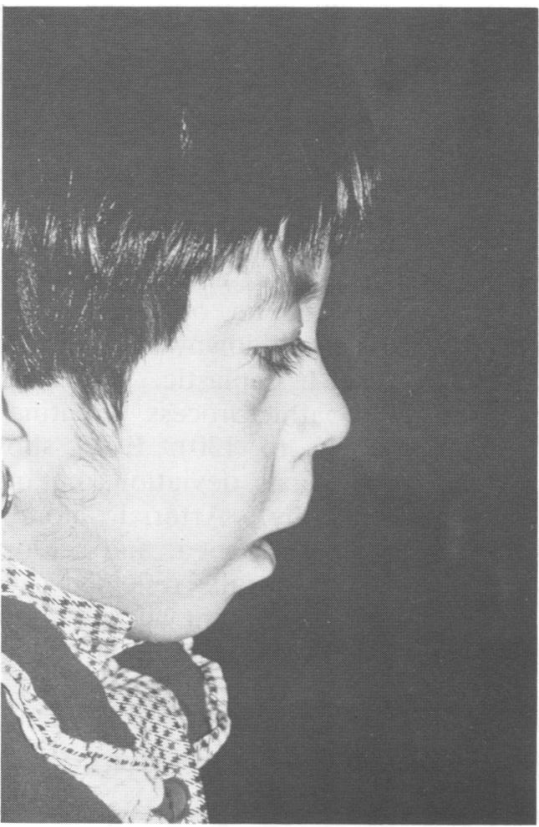

(d)

FIG 9d Patient 7 at three and a half years. Note long philtrum and micrognathia. 
stretched across the proximal interphalangeal and metacarpophalangeal joints of the left second, third, and fourth fingers. There was no limitation of movement at other joints of the upper limbs, but there was limited movement at hips, knees, and ankles. Hearing and intellect were normal. Height was $96 \mathrm{~cm}$ ( $3 \mathrm{rd}$ centile). Her appearance is shown in fig 9 (b, c, d).

\section{PATIENT 8 (FEMALE)}

Patient 8 is the second child of distantly related Jordanian parents. At her birth, the father was 31 and the mother 27 years. Four sibs are healthy. The pregnancy and delivery were normal and the child was reported to be 'small' at birth. Congenital scoliosis was present and there were sucking and feeding difficulties. Fixed flexion at the hips, knees, and ankles were noted at five years (although they may have been present earlier), at which time tenotomies at the ankles were done. Soon after, she began to walk with crutches. Independent walking began at seven years after bilateral femoral osteotomies for fixed flexion at the hips. She was of normal intelligence and attended a normal school.

She was admitted to this hospital at 11 years 9 months because of four severe 'chest infections' over the previous six months, for one of which she had been artificially ventilated. On examination she was small and thin, weighing only $13.9 \mathrm{~kg}$. There was respiratory distress with tachypnoea, pallor, and dehydration, but no fever. The chest was small and deformed and there was a very severe dorsal kyphoscoliosis. There was marked limitation of movement at the hips, knees, ankles, and feet (fig 10a) and antecubital and axillary skin webs were present (fig 10b). Marked muscle wasting of all limbs was noted but power and tone were normal. The mouth could not be opened widely. The palpebral fissures slanted downwards (fig 10c). The labia majora were hypoplastic. An EMG was suggestive of a myopathic process. Creatine kinase was $21 \mathrm{U} / \mathrm{l}$ (NR 15 to 130). ECG showed P pulmonale and right axis deviation, but no right ventricular hypertrophy. Arterial blood gases showed hypoxia, hypercapnoea, and acidosis. Respiratory function test results reflected severe respiratory restriction. Treatment with physiotherapy, aminophylline, and oxygen was given and the respiratory state temporarily improved, but several days after admission the child died suddenly. Necropsy was not performed.

PATIENT 9 (FEMALE)

Patient 9 is the second child of healthy, unrelated, Caucasian parents. The sib is well. Delivery was at 38 weeks and birth weight was $2041 \mathrm{~g}$. Multiple

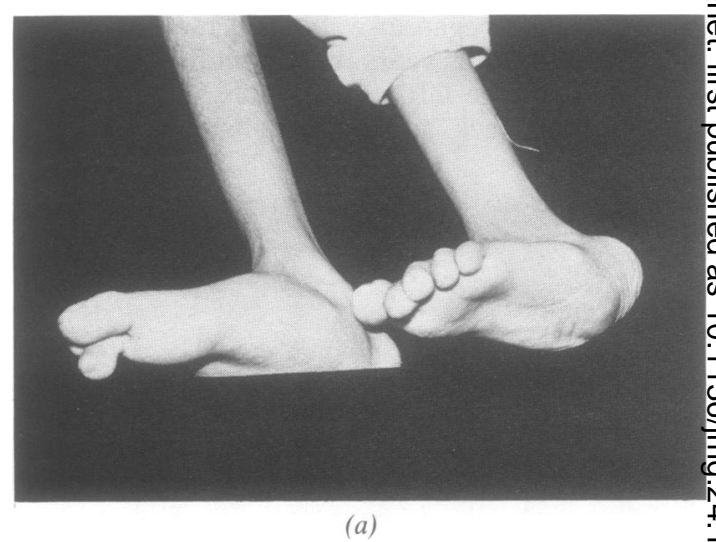

FIG 10a Patient 8 aged 11 years 9 months to show rockerbottom appearance of feet due to vertical tali.

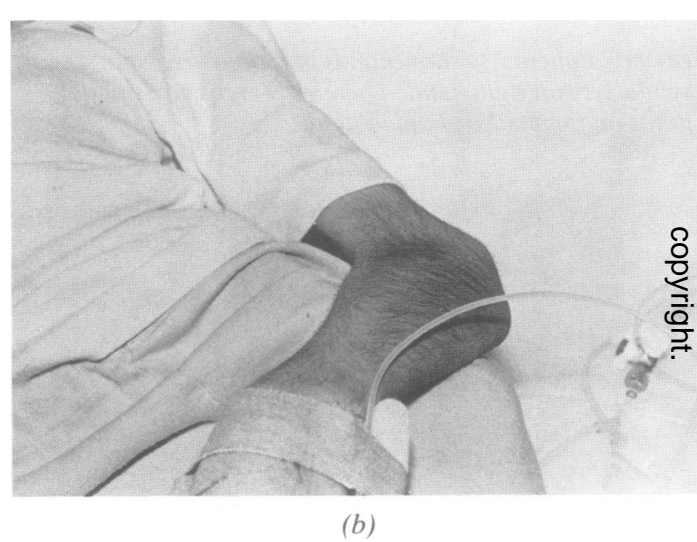

FIG 10b Patient 8 aged 11 years 9 months to show left antecubital pterygium.

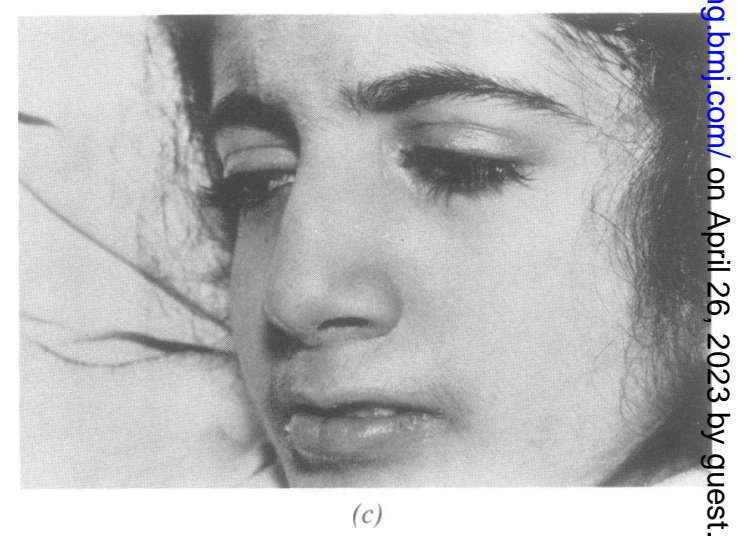

FIG 10c Patient 8. Note ptosis, downward slanting palpebral fissures, and small mouth. 
skeletal anomalies were noted at birth. The initial diagnosis was trisomy 18 (later changed to pseudotrisomy 18 , as the karyotype was normal $46, \mathrm{XX}$ ). Soon after beginning to sit at six months kyphoscoliosis developed, which gradually worsened. Episodes of dyspnoea occurred frequently and three apnoeic attacks required oxygen treatment. When assessed at two and a half years, her weight was $8.15 \mathrm{~kg}$ and height $67 \mathrm{~cm}$ (both well below the 3rd centile). Her facies was characteristic (fig 11a) and she could not open her mouth widely. The neck was short and there was severe dorsolumbar kyphoscoliosis. Range of movement was limited at all large joints and there were rockerbottom feet (fig 11b) and camptodactyly of fingers. Pterygia were present at the axillae, popliteal fossae, and lateral aspects of the neck. The genitalia and heart were normal. She could sit alone but was unable to walk. Mental development had progressed and she could put two words together.

\section{PATIENT 10 (MALE)}

Patient 10 was born to first cousin Muslim parents. At his birth, the mother was aged 35 years and the father 39. An older brother is healthy but three sisters died in infancy in Bangladesh and were said to have had similar abnormalities to patient 10. The pregnancy, delivery, and birth weight were said to be 'normal'. Deformities of the joints were present at birth. He began to walk at 18 months. When first examined at four years, he was a very small child (height $85 \mathrm{~cm}$, weight $10.9 \mathrm{~kg}$, OFC $47.5 \mathrm{~cm}$ ). There was limitation of movement at all the large joints with $40^{\circ}$ of fixed flexion at the knees. In the hands, flexion was limited at the MP and PIP joints and there were no transverse creases on the palms or fingers. Despite inability to make a fist, he had good hand function. Eversion and inversion of the feet was limited but there was no talipes. Skin webs were noted at the neck and popliteal fossae and there was an accentuated lumbar lordosis. The genitalia were normal. There was micrognathia, a high palate, inability to open the mouth widely, and large low set ears. Creatine kinase was normal $(1.8 \mu \mathrm{mol} / \mathrm{ml} / \mathrm{h}$, range 0.25 to 3.6 ) as was EMG. The patient was reevaluated aged $10 \frac{1}{2}$ years (fig $12 \mathrm{a}, \mathrm{b}$ ). Severe thoracic kyphoscoliosis had developed, but the degree of limitation at other joints was similar to the previous examination. $\mathrm{He}$ remained very small (height $105.4 \mathrm{~cm}$, weight $18 \cdot 5 \mathrm{~kg}$ ). Bilateral ocular ptosis was noted. He had not been unduly troubled by chest infections, but became breathless with exertion. Intellect was normal.

PATIENT 11 (MALE).

Patient 11 was born after a normal pregnancy and

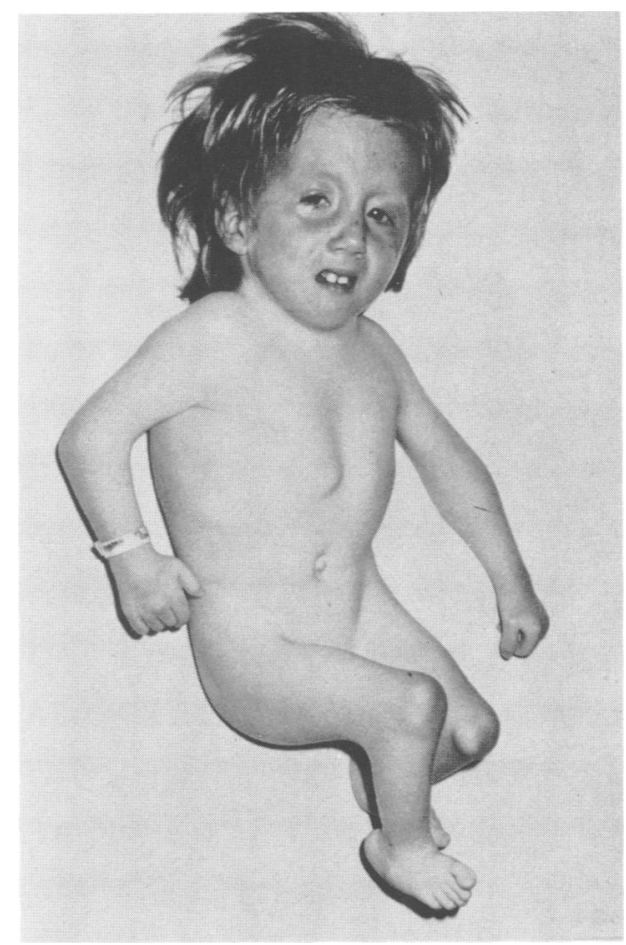

(a)

FIG 11a Patient 9 at two and a half years. Note ptosis, downward slanting palpebral fissures and angles of mouth, micrognathia, webbing at neck, right elbow, and right knee, and deformities of hands and feet.

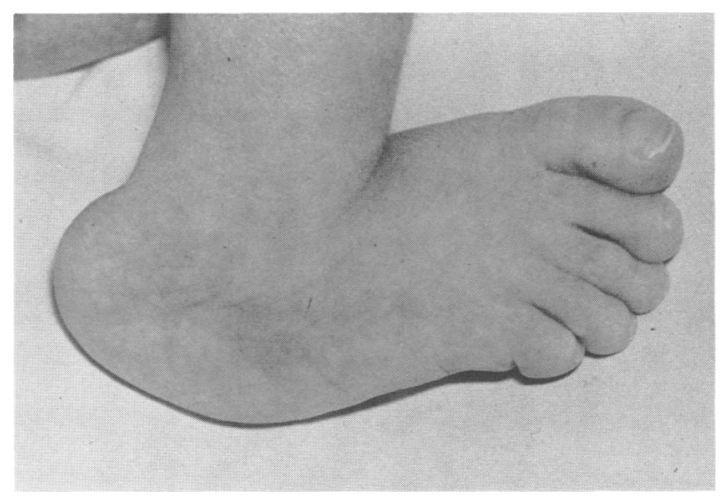

(b)

FIG $11 \mathrm{~b}$ Patient 9 . Note rockerbottom appearance due to vertical talus, and note the prominent heel. 


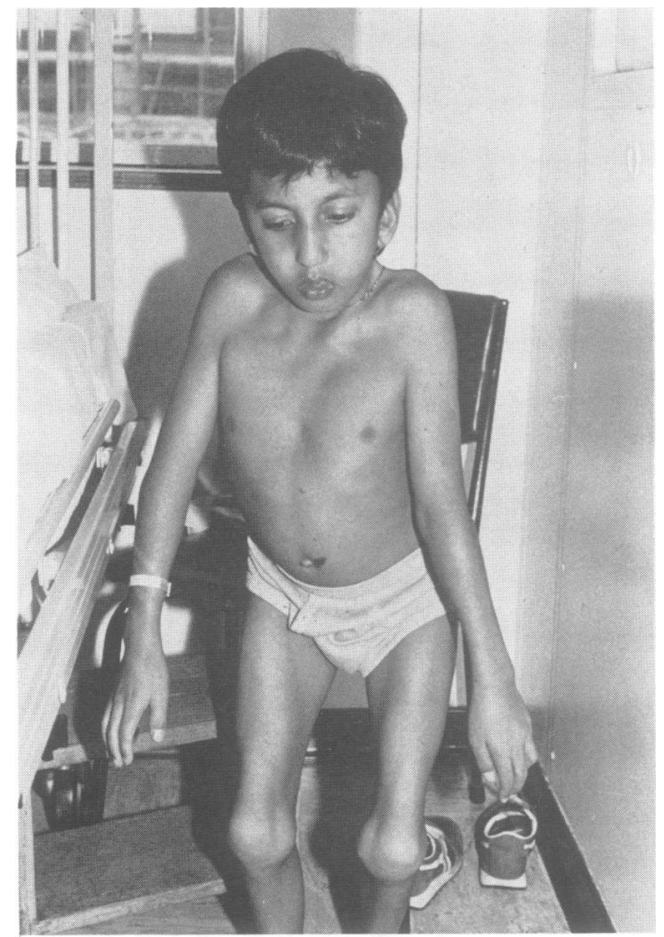

(a)

FIG 12a Patient 10 at $10^{1 / 2}$ years. Note scoliosis, fixed flexion at knees, and typical facial appearance.

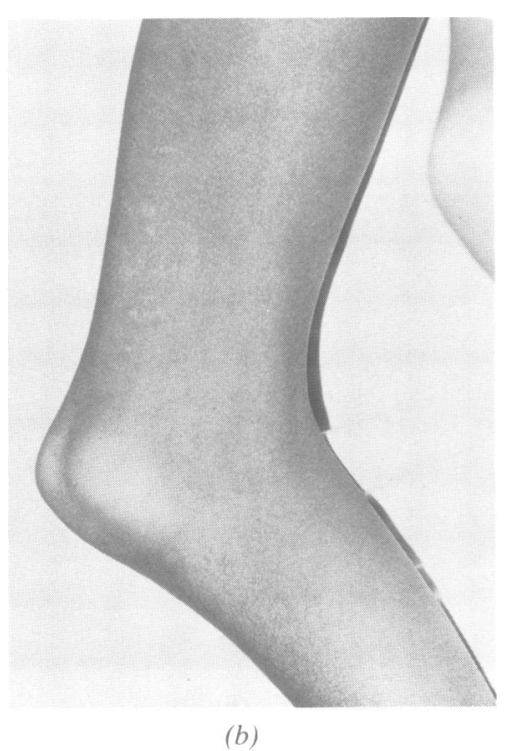

FIG 12b Knee of patient 10 to show popliteal pterygium. delivery at term. Birth weight was $2525 \mathrm{~g}$. The parents are unrelated Caucasians and there is one sib, a younger sister, who is well. Multiple join contractures and clubbed feet were noted at birth을 Attempts to correct the knee deformities at $18 \mathrm{D}$ months by manipulation and plaster casting were unsuccessful. Despite physiotherapy, flexion at the joints increased and scoliosis developed. When seen at three years, he was a very small, thin child (length $74.5 \mathrm{~cm}$, height $14 \mathrm{~kg}$ ), who was mentally alert. The following features were noted: asym $\vec{\omega}$ metrical skull, large, low set ears, small palpeפ bral fissures, bilateral ptosis more marked on the right, long upper lip, intact palate, micrognathia short neck, dorsal kyphoscoliosis, unusual deformityp of the chest (pectus carinatum and midline sternat depression), and partial fixed flexion at the knees hips, and elbows (fig 13a). The fingers were held flexed at the metacarpophalangeal joints, and the thumbs were small, proximally placed, and held across the palms. There were skin dimples at the wrists and elbows and the feet were in equinus position. The skin across the abdominal wall from the subcostal region to the pubis was noted to be

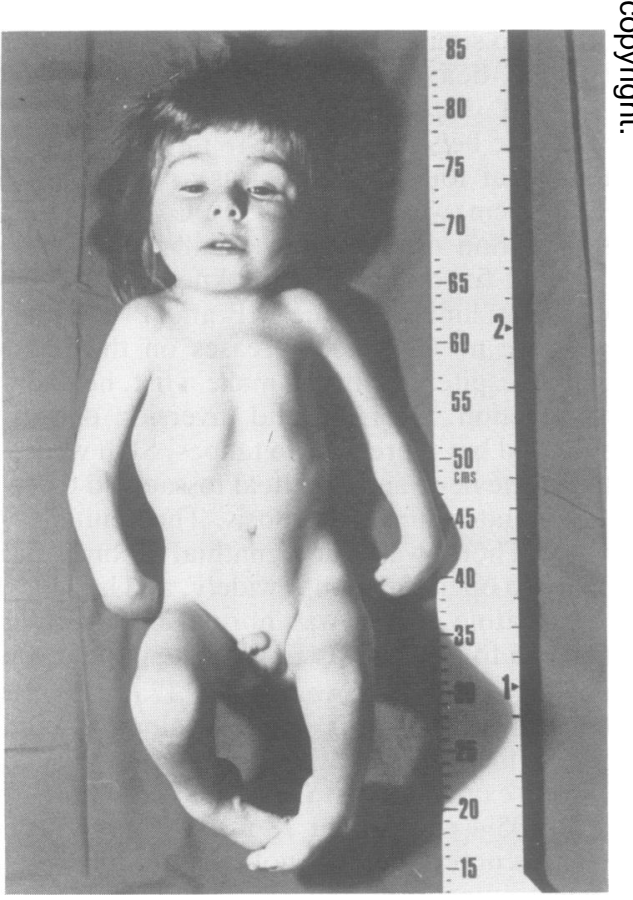

(a)

FIG 13a Patient 11 at three years. Note typical facial appearance, webbed neck, multiple deformities of joints andु of hands and feet. 


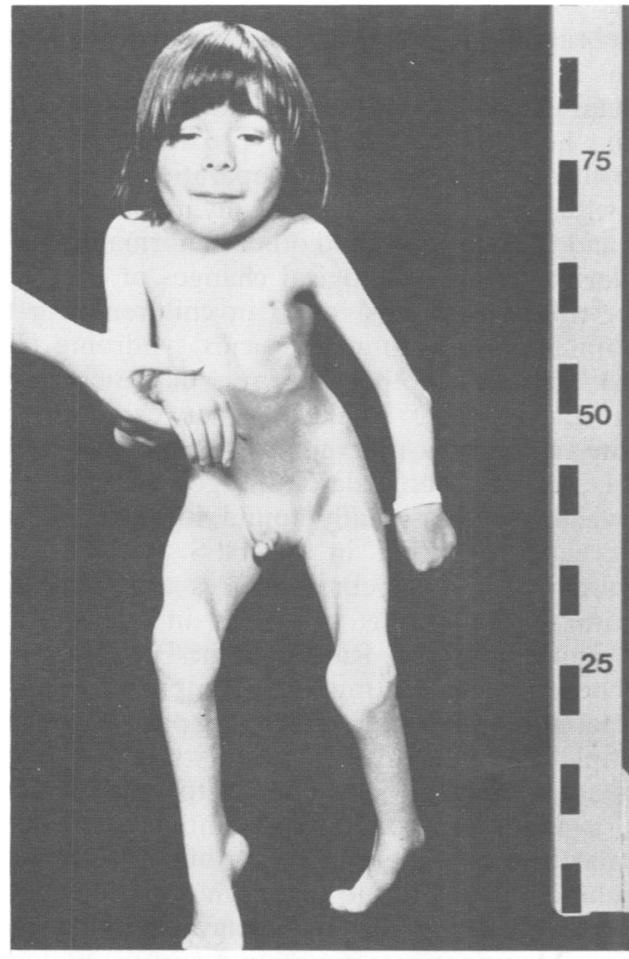

(b)

FIG 13b Patient 11 at eight and a half years.

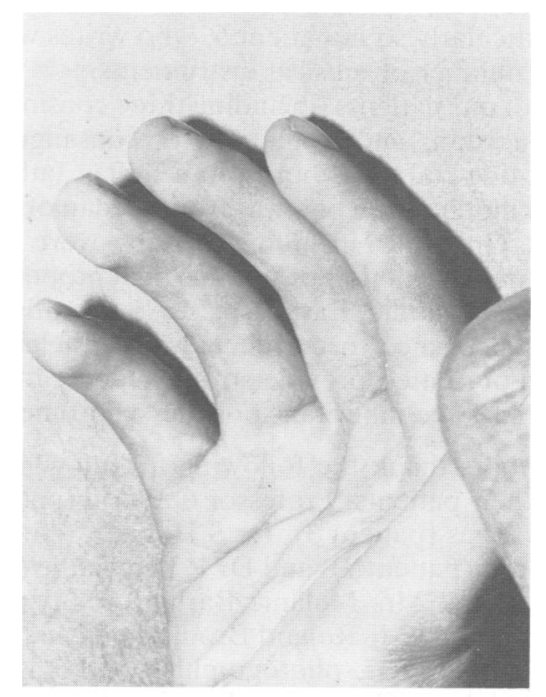

(c)

FIG 13c Hands of patient 11 at 11 years. Note absent finger flexion creases and unusual longitudinal palmar creases. Longitudinal skin webs span the MP joints. tight. He was unable to walk but 'bottom shuffled' and had a surprisingly good grip. Creatine kinase, electromyography, and nerve conduction velocities were normal. $\mathrm{G}$ banded chromosomes were normal $(46, X Y)$. A CT brain scan showed wide basal cisterns but no other abnormalities.

When seen at eight and a half years, the kyphoscoliosis had progressed (fig 13b). He was able to walk about 100 yards. No definite skin webs were present apart from mild syndactyly, but the skin seemed tight across the joints. Intelligence was normal. He suffered recurrent chest infections.

Additional features noted at 11 years were that he had no finger flexion creases and very few palmar ones, but the hands could be flexed passively (fig 13c). He had limited ability to open the mouth widely. Spectacles for short-sightedness had been worn for the last two years. A school hearing test had revealed mild right sided hearing loss. It was at this time that the diagnosis of multiple pterygium syndrome was made.

\section{Discussion}

In their review, Hall et $a l^{4}$ list 15 entities with limb pterygia, including autosomal dominant and recessive forms and those with chromosomal defects, all of which are individually rare. All our patients apart from patients 3 and 11 closely resemble those with the commonest recessive form, the multiple pterygium syndrome. Although patient 3 had a normal face apart from micrognathia at birth, and no detectable skin webs, the similarity of the pattern of multiple contractures to that of his two affected cousins (patients 1 and 2), and the consanguinity of his parents, make it likely that he too had the multiple pterygium syndrome. Patients 1 and 2 also did not develop webs until after birth. Indeed, in only three of the 11 patients were webs specifically noted at birth (patients 4,5 , and 6); in all three, these included lateral neck webs. While it is possible that congenital pterygia in the others could have been overlooked or not recorded, it is important to be aware that lack of webbing at birth does not exclude this recessive syndrome.

Patient 11 had only minimal webbing, namely syndactyly and 'tight skin' across joints. It is likely that he does have the multiple pterygium syndrome, given the similarity to the other patients in terms of the pattern of joint contractures, the facial appearance, short stature, and vertebral anomalies. Marked variability both between and within families has been noted previously, ${ }^{245}$ especially with respect to the number and type of webs found. ${ }^{4}$

The conductive deafness of patients $4,5,6$, and 11 and associated abnormalities of the middle ear 
ossicles (documented at necropsy in patient 5 and at operation in patient 6 ) are similar to the abnormality in another patient, a girl, who had bilateral absence of the long process of the incus and hearing loss. ${ }^{2}$ Others reported with hearing loss include a female with unilateral hearing loss detected at six years for which a hearing aid was given ${ }^{6}$ and patients 3 (male) and 5 (female) described by Hall et $\mathrm{l}^{4}$ who each had unilateral hearing loss. Hearing loss, perhaps secondary to defective ossicles of the ear, may be part of the syndrome and audiological testing is indicated.

Several other points are noteworthy.

Respiratory impairment, congenital heart disease, and mortality. Five patients $(1,5,7,8$, and 11$)$ suffered recurrent chest infections and patient 9 had episodes of dyspnoea and apnoea. Patient 6 had one severe chest infection which required treatment in intensive care and patient 10 had dyspnoea on exertion. Presumably these respiratory complications relate to the small chest size, secondary to severe dorsal kyphoscoliosis. Patients 5 and 8 both had severe kyphoscoliosis and succumbed to respiratory failure in childhood. Of the 49 cases summarised by Hall $e t$ $a l,{ }^{4}$ at least three had died in childhood as a result of pneumonia (case 1 of Norum et al died at one year, patient 4 of Chen $e t l^{5}$ at one month, and the patient of Lang et al $^{8}$ died at 13 months). The high incidence of respiratory problems (eight out of 11 cases in our series) may be an argument for active treatment of spinal deformity.

Congenital heart disease has been reported in several cases. Golden and Lakin ${ }^{9}$ described two brothers (cases 1 and 2) as "formes fruste of the Marfan syndrome". They had pterygia, severe scoliosis, camptodactyly, and club feet and are now accepted as having the multiple pterygium syndrome. ${ }^{4}$ Both had a heart murmur, clinically consistent with a congenital atrial septal defect in case 1 and shown to be an ostium-secundum type ASD at necropsy in case 2 . The patient described by Martischnig and Swoboda ${ }^{10}$ had VSD. Patient 4 of Hall $e t a l^{4}$ had a congenital systolic murmur of "no clinical significance". Our case 3 died at six weeks of complex congenital heart defect.

Skeletal abnormalities in the multiple pterygium syndrome are numerous. Kyphoscoliosis is usually present, may be congenital, and is often severe. It involved the dorsal spine in all our cases and extended to the lumbar region in one (patient 9). Vertebral anomalies including failure of posterior fusion of vertebrae or fusion of cervical vertebrae (and rib anomalies) occurred in $27 \%$ of the series of Hall et al. ${ }^{4}$ Similar vertebral anomalies occurred in nine of 11 of our cases and also included anterior clefts of the vertebral bodies and tall narro $\stackrel{\mathbb{B}}{\vec{D}}$ vertebral bodies. Vertical talus and absent patellae have also been documented previously. Othe skeletal defects in our patients included dislocatio of the head of the radius or proximal radioulnaf synostosis, distal radioulnar separation, long clavien

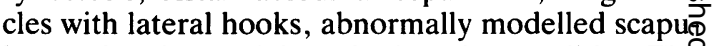
lae, and various pelvic and other abnormalities. The्ष similarity of the radiological changes of the verte brae, ribs, and radius found in children with the femoral hypoplasia-unusual facies syndrome ( $\mathrm{FH} \dot{ }$ UFS) whose mothers were diabetic is of interest. ${ }^{1112}$ Other similarities between that syn drome and multiple pterygium syndrome are microge nathia, talipes, cleft palate, and genital anomalies Pterygia are occasionally found in the FH-UFS. Differences are that in FH-UFS, cleft lip and upward slanting palpebral fissures are found and्ट femoral hypoplasia is not seen in the multiple pterygium syndrome. Rarely, in the FH-UFS, there may be a history of intrauterine compression leading to fetal immobility, ${ }^{13}$ an interesting parallel with th multiple pterygium syndrome, in which immobilit禺 pre- and postnatally is believed to occur. ${ }^{45}$

It is important to note that intellect is usualli normal, although there is danger of mental retarda $\overrightarrow{0}$ tion being assumed due to the multiple congen $99^{\circ}$ defects, misdiagnosis, and delayed motor mife stones. Many patients maintain a surprising degtee of mobility, despite their disabilities. Manua dexterity is often considerably better than would be predicted from the appearance of the hands. Thi was particularly so in patient 6 , who writes well an\& plays a number of musical instruments.

Five of our patients (including three cousins) were from Pakistan, and were born of consanguineous unions, one child was born of an Indian father an 8 English mother, and one was from Jordan of related parents. Only four, including two sibs, were Britisk? It is unknown whether or not this high proportion of Asian and Middle Eastern cases is significant of simply a chance occurrence. Nevertheless, the families presented provide strong support for auto somal recessive inheritance of the syndrome. 옹

The authors thank the following for allowing us report their patients: Professor C Wood (patient 2 ) Dr P G Rees (patient 3), Dr S Herman (patient 6) Dr E Brett (patient 7), and Dr R Dinwiddie (patienty 8). We thank Mrs Melanie Barham for typing the् manuscript and Mr Roland Brooks and Miss Gilliag్ Almond for their photographic work. EMT supported by a Wellcome Training Fellowship.

References

1 Gorlin R, Pinborg JJ, Cohen M. Syndromes of the head an neck. 2nd ed. New York: McGraw-Hill, 1976. 
${ }^{2}$ Escobar V, Bixler D, Gleiser S, Weaver DD, Gibbs T. Multiple pterygium syndrome. Am J Dis Child 1978;132:609-11.

${ }^{3}$ Smith DW. Recognizable patterns of human malformation. 3rd ed. London: Saunders, 1982.

${ }^{+}$Hall JG, Reed SD. Rosenbaum KN, Gershanik J, Chen H. Wilson KM. Limb pterygium syndromes. A review and report of eleven patients. Am J Med Genet 1982:12:377-409.

5 Chen H, Chang CH, Raghunath PM, Peters HA, Grijalva NS, Opitz JM. Multiple pterygium syndrome. Am J Med Genet 1980:7:91-102.

${ }^{6}$ Scott CI. Pterygium syndrome. Birth Defects 1969;V(2):231-2. 7 Norum RA, James VL, Mabry CC. Pterygium syndrome in three children in a recessive pedigree pattern. Birth Defects $1969 ; \mathbf{V}(2): 233-5$.

* Lang VK, Lelbach WK, Colmant HJ. Beitrag zum Bilde der Pterygomyodysplasia arthrogrypotica generalis (pterygoarthromyodysplasia congenita). Monatsschr Kinderheilkd 1960;108:248-52.

${ }^{9}$ Golden RL, Lakin H. The 'forme fruste' in Marfan's syndrome. $N$ Engl J Med 1959;260:797-801.

10 Martischnig E. Swoboda W. Arthrogryposis multiplex congenita und Pterygium syndrom. Monatsschr Kinderheilkd 1952:100:225 .

" Johnson JP, Carey JC, Gooch M, Petersen J, Beattie JF. Femoral hypoplasia-unusual facies syndrome in infants of diabetic mothers. J Pediatr 1983;102:866-72.

12 Assemany SR, Muzzo S, Gardner LI. Syndrome of phocomelic diabetic embryopathy (caudal dysplasia). Am J Dis Child 1972:123:489-91.

13 Burn J. Winter RM. Baraitser M. Hall CM. Fixsen J. The femoral hypoplasia-unusual facies syndrome. J Med Genet 1984:21:331-40.

Correspondence and requests for reprints to Dr E M Thompson, Department of Clinical Genetics, The Hospital for Sick Children, Great Ormond Street, London WC1N 3JH.

APPENDIX Other radiological details.

PATIENT 3

Dysharmonious bone maturation.
PATIENT 5

Widening of symphysis pubis and of ischiopubic synchondroses. Bilaterally subluxed femoral heads. Prominent frontal bone and marked convolutional markings of skull.

PATIENT 6

Triangular fourth sacral segment, leading to a right angled bend in sacrum. Pelvis showed narrow, small iliac wings, large ischia directed downwards, and protrusio acetabulae.

PATIENT 8

First metacarpophalangeal joint of right hand subluxed. Left patella very small and dislocated (no film of right knee).

PATIENT 9

Secondary inferior hooks at the kyphoscoliosis. Pelvic configuration same as patient 6 .

PATIENT 10

Iliac wings of pelvis flared. Fused lunate and triquetrum at wrists with abnormally small carpal centres.

PATIENT 11

Proximal pseudoepiphyses of second and fifth metacarpals. Horizontally placed lunate bones of wrist and small scaphoid bones. Small capital femoral epiphyses. Broad femoral necks. Generally, flared metaphyses and small epiphyses of long bones. Radius and ulna abnormally short and abnormally modelled. 